\title{
POPULATION GROWTH AND BIRTH-CONTROL
}

\section{A BIOLOGICAL STUDY}

\author{
By Colonel C. A. GILL, I.M.S., K.H.S., M.R.C.P. (Lond.), \\ D.P.H. (ENG.), D.T.M \& H. (ENG.)
}

Rangoon, Burma

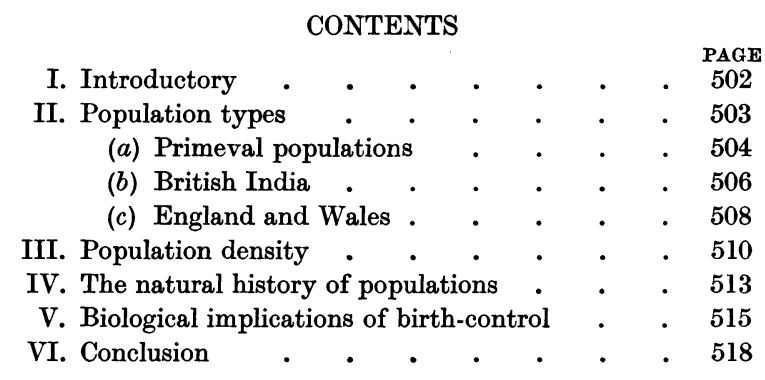

\section{INTRODUCTORY}

During the Spring Session (1934) of the Burma Legislative Council, a member of the Council-the only lady member-submitted the following resolution:

"This Council recommends to Government that immediate steps be taken to prevent the sale of medical preparations for preventing or controlling childbirth."

The resolution did not survive the ballot, and it did not therefore come up for discussion, but the population problem is now attracting widespread public attention, and the recent rapid increase of the population of India has led to a demand for the inception of preventive measures.

So long as the birth-control movement was confined to Western Europe, India was not directly concerned, but the advocates of the employment of contraceptives, encouraged perhaps by the success attending their activities in England, are now turning their attention to India, and it appears to have been decided, at a recent conference held under the auspices of the BirthControl International Information Centre, to inaugurate an active birthcontrol campaign in India in the near future. In these circumstances, the present moment is peculiarly opportune for an examination of the principles upon which the practice of artificial birth-control is based; and this is the more necessary, since, although birth-control in one form or another has long been practised in many western countries, no attempt appears to have been made to determine the biological implications attaching to interference with population growth. It is, indeed, doubtful whether the need of such an enquiry is realised. The rate of increase of the population in many countries 
is so rapid, the laws of Malthus are so inexorable, and the warnings of medical experts, economists, and sociologists are so insistent, that artificial birthcontrol has come to be accepted as an unavoidable, if unpleasant, necessity of modern civilisation. Nevertheless, important as the economic aspect of the question may be, artificial birth-control raises far wider issues. Birth-control involves interference with reproduction, and, since reproduction constitutes the raw material of evolution, no instructed biologist would be prepared to deny that it is necessary to understand the implications attaching to interference with population growth before it is permissible to regard artificial birth-control as a practice sanctioned by science. The immediate purpose of the present enquiry was to determine the biological implications of artificial birth-control, but it soon became apparent that the absence of precise knowledge regarding the fundamental principles underlying the growth of populations prevented any satisfactory answer being given to this question. It was, accordingly, decided to endeavour to elucidate the basic principles underlying the growth and development of populations in the hope that it would become possible to arrive at definitive conclusions in regard to the biological implications of birth-control.

\section{Population types}

That the population of any given area must be regarded not merely from the point of view of its numbers, but also from the standpoint of the forces determining changes or "movements" of the population is well known. It is also recognised that "movements" of a population (apart from migratory movements) are largely determined by the forces controlling the birth-rate and the death-rate. In these circumstances it is clear that the total population of any given area at any given time represents (apart from the effect of migration) the level at which the forces concerned in controlling the numbers of a population are in equilibrium. It must therefore be inferred that if these forces remain constant, the population must remain constant, whilst inconstancy of these forces will be associated with "movements" of the population. It follows therefore that unless these forces are known and are taken into account, any attempt to determine the rate of growth of a population or to predict the total population in the remote future is not likely to be attended with success. It is necessary to emphasise this point, since the method usually employed in the study of population problems is the statistical method, which, inasmuch as it ignores the existence of the forces concerned in determining "movements" of the population, cannot be regarded as an entirely reliable method of throwing light upon the rate of growth of populations. This fact is well illustrated in the case of the population of India, which, it was estimated (in the year 1927), on the basis of the statistical analysis of populationgrowth curves, would reach 330 millions in the year 1971, whereas the population enumerated at the census in the year 1931 was 353 millions-a figure which should not have been reached, according to the statistical calculation, 
until about the year 2110. [A recent revised forecast, based upon the census of 1931, predicts that the population of India will reach 400 millions about the year 1941.]

So far as India is concerned, therefore, estimates based upon populationgrowth curves are unreliable, and the inferences drawn therefrom must, in consequence, be accepted with reserve. It is proposed, therefore, to discard the use of this method, and the proposition it is desired to establish here is that a population must be regarded as a biological entity and that, in consequence, the biological constitutes the proper line of approach to the study of population problems. But populations from the biological point of viewmankind in the mass-possess other attributes beside numbers. It is, in fact, well known that populations vary widely both in structure and in composition; indeed, so great are the variations in respect of age composition that it is not ordinarily possible to compare the vital statistics of different countries, or even of different communities in the same country, until the statistical data have been "corrected" and standardised.

A population must therefore be regarded as a biological entity with a variable content, and this content may be regarded as constituting its biological structure. But if, as is admitted, populations vary widely in structure, it follows that it should be possible to classify them, in accordance with their structure, into "population types."

The first step therefore in the study of populations from the biological standpoint involves the differentiation of population types; and in order to enable this to be done, it is necessary to devise indices or statistical data representative of the biological structure of populations. A number of such indices are fortunately available, since many of the statistical data commonly used by public health authorities are suitable for this purpose. These indices, together with a few others specially designed to throw light on the biological structure of populations, are detailed in Table I. Their significance will be discussed later, and it will be sufficient to remark here that these indices, which will be referred to under the collective term of the "population plexus," comprise a series of statistical data designed to provide a convenient means whereby population types can be differentiated and compared. In this manner it is found that populations of at least five distinct types can be differentiated, but in this study attention will be concentrated upon three population types which have been selected on account of the highly distinctive character of the population plexus.

\section{(a) Primeval populations}

One of the oldest communities of which any records exist are the patriarchal tribes whose life history is depicted in the Book of Genesis, and this community has therefore been selected as an example of a primeval population.

It is, however, not feasible, owing to the absence of records, to display the biological structure of this population in statistical terms; nevertheless, there 
is reason to believe, even if there were no primitive tribes at the present day, that it would still be possible to appraise with rough accuracy the salient features of the population plexus of this community. The conditions of life of the pastoral inhabitants of an inhospitable region, with no knowledge of agriculture, must have been exacting, and the tenure of life of a people exposed to great vicissitudes of climate, to pestilence and famine, and to the attacks of human and other enemies must have been extremely insecure. In these circumstances, it may be inferred that the death-rate must have been high, and the mean duration of life-although there may have been remarkable exceptions in individual cases-must have been short.

The hardships of life would fall with particular severity upon the weaker sex, and on this account, and also because of the added dangers associated with childbirth, the female death-rate must have been relatively high, and the male population, in consequence, must have exceeded the female population. The precarious conditions of life, combined with the scarcity of women, would necessitate early marriage and, in consequence, the birth-rate and fertility-rate would both be high. But high natality being associated with high mortality, the rate of growth of the population would be slow.

There is much evidence in the Book of Genesis of the general accuracy of these surmises, and it will shortly be shown that the population plexus of primitive races at the present day exhibits precisely similar features. Nor is it difficult to understand the significance of this population plexus. It is in fact abundantly clear that the motif of much of the folklore enshrined in the old Testament is the urge of race survival. Thus in almost every chapter of the Book of Genesis, the paramount necessity of prolificity, as a means of race survival, is stressed. This seems to be the explanation of early marriages. It also accounts for polygamy, since the survival of the tribe could not be allowed to depend upon the precarious life of a single female; and it explains exogamous marriages and even incestuous unions.

It is clear that race survival, rather than the philoprogenitiveness or sexuality, was the paramount consideration, since emphasis is everywhere laid, not upon the desire for offspring or the sexual urge, but upon the need of the multiplication of the seed for the purpose of the founding of nations and of kingdoms to occupy the earth. That the urge of race survival transcended even the sexual urge is strikingly illustrated by the wives of Abraham and of Jacob, who, when they feared they were past child-bearing, urged their husbands to take their handmaidens to wife. The urge that will make a wife willing to share her husband with another woman must indeed be strong, and it is not easily explained except on the assumption that in a primeval community, the urge of prolificity, as a means of race survival, overrides the desire for parenthood and even the sexual instinct. In such circumstances, it would be expected that every woman would desire to bear as many children as possible, and more particularly male children. There are innumerable instances of the existence of this trait, of which Rachel's plaintive cry, "Give 
me children or else I die," affords a good example. The interpretation of the population plexus of a primeval population would thus appear to be that in the earliest stage of population growth prolificity is a biological necessity of transcendental importance. It accounts for much of the folklore of the Old Testament, it explains and in large measure justifies many apparently dysgenic habits and customs, and lastly, it is an important factor in determining the biological structure of the population.

\section{(b) British India}

It is dangerous to generalise regarding a country almost as large as Europe (without Russia) and about a population equal to nearly one-sixth of the human race. Nevertheless, it is thought that the great agricultural community that constitutes about 90 per cent. of the total population of India may be regarded as a homogeneous entity from the standpoint of the structure of the population. It is proposed therefore to utilise the vital statistics of British India for the purpose of determining the population plexus of India. The statistical indices are given in Table I, together with, for the purpose of comparison, the corresponding data in respect of England and Wales.

\section{Table I. The population plexus of British India and of England and Wales}

(1) Population-growth index

(2) Natural increase (population)

(3) Adolescent index

(4) Longevity index

(5) Sex-ratio (population)

(6) Urbanisation index

(7) Birth-rate

(8) Fertility-rate

(9) Sex-ratio (births)

(10) Death-rate

(11) Infantile mortality-rate

(12) Sex-ratio (deaths)

$\begin{array}{cc}\text { British } & \text { England } \\ \text { India } & \text { and Wales } \\ 47 & 50 \\ 9 \cdot 2 & 3 \cdot 5 \\ 40 & 24 \\ 10 & 22 \\ 94 & 109 \\ 3 \cdot 6 & 39 \cdot 1 \\ 34 & 15 \cdot 8 \\ 145 & 75 \\ 108 & 104 \\ 24 \cdot 8 & 12 \cdot 3 \\ 179 & 66 \\ 116 & 84\end{array}$

\section{Explanation}

(1) The population-growth index represents the percentage increase of population during the period 1881-1930.

(2) Natural increase (population) represents the excess of the birth-rate over the death-rate during the year 1931.

(3) The adolescent index represents the percentage of the population under 15 years of age in the year 1931 .

(4) The longevity index represents the percentage of the population over 50 years of age in the year 1931 .

(5) The sex-ratio (population) indicates the number of females per 100 males.

(6) The urbanisation index represents the percentage of the population living in towns having a population of 10,000 or over in 1926 .

(7) The birth-rate is the crude rate per mille of population in the year 1931 .

(8) The fertility-rate represents the ratio of births per 1000 women (married or otherwise between the ages of 15 and 40 years in the year 1931 .

(9) The sex-ratio (births) indicates the number of male children born alive for every $10 \mathrm{C}$ female children.

(10) The death-rate is the crude rate per mille of population in the year 1931. 
(11) The infantile mortality-rate represents the number of deaths of children under one year of age per 1000 births in the year 1931 .

(12) The sex-ratio (deaths) represents, in the case of India, the number of female deaths between the ages of 15 and 40 years per 100 male deaths calculated on the male and female death-rate of this age group in the year 1931. The figure for England and Wales refers to the age period $15-45$ years and to the years $1891-5$.

The significance attaching to these indices will be discussed later. It may, however, be remarked here that, since the sex-ratio (population) and sex-ratio (deaths) in some measure reflect the conditions of life of the female section of the population, these ratios may, with reservations, be regarded as carrying ethical implications. A scrutiny of the figures given in Table I permits of the main features of the population plexus of British India being summarised as follows:

The population is essentially youthful, the younger age groups being predominant, the mean duration of life is short, and the interval between generations is consequently small. The birth-rate and fertility-rate are absolutely and relatively high, but the death-rate is also high, so that, in spite of the high fertility-rate and, in some years (such as 1931), the large natural increase of the population, the rate of growth of the population is relatively slow. Finally, there is a paucity of females and the female death-rate is relatively high.

These features, apart from periodical sharp rises of the death-rate (as the result of epidemics), have exhibited no conspicuous variations during the past 50 years, and it must therefore be concluded that no appreciable change in the structure of the population has taken place during this period. The survival of a population peculiarly prone, in the past, to decimation by war and by famine, and, in the present, by widespread epidemics of great intensity, must necessarily be dependent upon its rapid and constant replenishment, and in this fact is largely to be found the key to the interpretation of the population plexus of India. It thus accounts for the universality of marriage, and for marriage at puberty or earlier, which, in turn, largely explains the high birth-rate, the high fertility-rate, the relatively high female death-rate and the relative dearth of females. Finally, the high birth-rate explains, in part at any rate, the high total death-rate, since in India children under one year of age ordinarily contribute about one-fourth and children under 10 years ordinarily contribute about one-half of the total mortality. We thus see that, as in the case of primeval populations, the biological structure of the population is in large measure determined by the urge of prolificity.

There is, however, no evidence that this urge is dictated by the urge of race survival. On the contrary, the urge of prolificity in India takes the form, as is well known, of a passionate desire to ensure the survival of the family. In the presence of high infantile mortality, large families are a necessity and philoprogenitiveness becomes a duty sanctified by religion or prescribed by custom, which few would wish and still fewer would dare to shirk. 
In these circumstances it is not surprising that the desire of every woman should be to bear as many children, especially male children, as possible; nor is it difficult to understand why marriage usually takes place at puberty, why a barren wife may be divorced, and why polygamy, although rarely practised amongst the poor, is usually permissible. In India therefore prolificity as a means of family survival must be regarded as a biological necessity, and to this fact must in large measure be ascribed many of the religious observances and habits and customs of rural India.

It would thus appear that, as in the case of primeval populations, the urge of prolificity is correlated with the biological need of prolificity, from which it may be inferred that habits and customs that subserve the purpose of stimulating reproduction are charged with biological significance. A population exhibiting the population plexus characteristic of rural India may be regarded as in an early stage of population growth, and, as such, it may be defined as a "nascent" population.

\section{(c) England and Wales}

A scrutiny of the figures given in Table $\mathrm{I}$ in respect of the biological structure of the population of England and Wales permits of the following brief summary:

The population of England and Wales is an "aged" population owing to the relative predominance of the older age groups. It is also a long-lived population, the mean duration of life and the interval between generations being relatively long. The birth-rate is absolutely low and it is also relatively low as compared with British India, and so also is the fertility-rate. The death-rate and the infantile mortality-rate are also absolutely and relatively low as compared with the corresponding Indian rates, and, on account of the small excess of the birth-rate over the death-rate, the natural increase of the population is small.

The sex-ratios differ markedly from those of British India, since females outnumber males and the female death-rate at all age periods (except 1-5 years) is lower than the male death-rate, the difference in the sex-ratio of deaths in England and Wales and in British India respectively being particularly marked during the child-bearing period.

A study of the vital statistics during the past 100 years shows, however, that the population of England and Wales, unlike the population of British India during the past 50 years, has not exhibited constant features. Thus, the population of England and Wales, which in 1801 numbered 9 millions, was approximately 40 millions in 1931, which represents an increase of 340 per cent. in 130 years. From 1871 to 1900 , the decennial rate of increase varied between 12 and 18 per cent., but, during the decade 1911-20, the rate of increase fell to 4.9 per cent., and to 5.5 per cent. during the last decennium (1921-30). This decline in the rate of growth of the population has been associated with a steady decline of the birth-rate. Thus the birth-rate, which 
was 35.4 during the period 1871-80 (as compared with 34 in modern India), has steadily declined since this date until it reached 14.4 in the year 1933. Scarcely less striking has been the steady decline of the death-rate, which fell from $21 \cdot 4$ in the decennial period 1871-80 (as compared with 24.8 in modern India) to $12 \cdot 1$ during the last decennial period. That the decline of the birthrate has occasioned a profound change in the age composition of the population, and thereby materially altered the biological structure of the population, is well known. Further, the decline of the birth-rate is in some measure responsible, owing to the relatively high death-rate during the early years of life, for the decline of the death-rate; indeed, it is to this circumstance, rather than to the achievements of modern medical science (which are mainly reflected in the longer life and better health now enjoyed by the population of England and Wales), that the decline of the death-rate is chiefly due. There is, however, a limit to the extent to which death can be postponed, and it therefore follows, if the existing tendency of the birth-rate to decline is maintained, that, as the population "ages," the death-rate must rise until it equals or exceeds the birth-rate. It is in fact estimated, assuming no change in the forces determining population growth, that the population of England and Wales will attain its maximum about the year 1950. But apart from the attainment of equilibrium between births and deaths, which may occur fortuituously in any country, the population plexus of England and Wales exhibits certain features which serve to distinguish it sharply from that of British India and, indeed, of most other civilised and semi-civilised countries. Thus, not only is the high longevity index, the low infantile mortality and high urbanisation index of the population of England and Wales indicative of an advanced state of civilisation, but the sex-ratios which reflect in some measure the high status of the female sex carry implications of an ethical order. It is proposed to apply the term "mature" to populations exhibiting this combination of features and to classify as "immature" those populations that have passed the nascent stage but do not exhibit the characteristic features of "mature" populations. In view of the effect of the declining birth-rate in changing the biological structure of the population of England and Wales during the past 50 years, it is necessary to consider the circumstances responsible for the decline. The Registrar-General of England and Wales has shown that the decline of the birth-rate is correlated with a decline of the marriage-rate and to the postponement of marriage. He points out that, as a result of these two circumstances, the fertility-rate has declined, partly on account of the reduction of the period of potential fecundity, and partly by the curtailment of the period of maximum fertility in women (18-25 years). The Registrar-General, however, states that the decline of the birth-rate cannot be wholly attributed to these causes, and he opines that nearly 70 per cent. of the decline of the birth-rate must be attributed to the artificial restriction of births. It is possible that other factors may also have contributed to the decline of fertility; thus the postponement of the average age of marriage of 
females from 17 to 22 years would reduce the apparent fertility-rate of married women by rendering it almost impossible for women belonging to two generations to bear children contemporaneously. Again, the possibility of a real decline of fertility in modern England cannot be excluded. But, whether this surmise be correct or not, it is scarcely open to doubt that a large part of the decline of the birth-rate in England (and also in France and in certain other countries) during the past 30 years is due to the artificial restriction of births. It is therefore clear that the remarkable change that has taken place in the population-plexus of England and Wales during the past 50 years has, in large measure, been brought about, not by uncontrollable natural forces, but by purposive acts upon the part of man. In the first place, there is the postponement of marriage, which is a reflection partly of the higher position and greater freedom accorded to women, and partly of the higher standard of living and the larger individual efforts necessary to maintain that standard at the level considered requisite in modern England. Secondly, there is the deliberate limitation of families, which has been facilitated and rendered possible by a conspicuous change in the attitude of married women towards maternity. It is in fact clear that, since the survival of the family can, in modern England, usually be assured by the birth of one or two offspring, the desire for, as well as the need of large families has in large measure disappeared. Prolificity, as a means of race survival or even of family survival, is thus no longer a biological necessity of prime importance in modern England, and, correlated with this fact, maternity has come to play a relatively small part in the life of the modern English woman.

It is for consideration therefore whether these purposive acts-and here no biological distinction can be drawn between the natural and artificial restriction of births-whereby the birth-rate and the fertility-rate has been reduced and the biological structure of the population has been changed, should not be regarded as expressive of an instinctive reaction upon the part of man to his biological environment, in the same manner as, it has been suggested, is the intense philoprogenitiveness of a primeval people.

Be this as it may, it must be concluded that, as a civilised population approaches maturity, natural forces come into play which tend to slow down the rate of population growth until, so far as vegetative increase is concerned, growth may cease entirely.

\section{Population Density}

Hitherto the forces determining the growth of populations have alone been considered, but it is now necessary to refer to the factors limiting population growth or, in other words, determining the density of populations.

It is axiomatic, since life cannot be maintained without food, that no population can remain permanently above subsistence level. The proposition that all large homogeneous populations tend to increase is likewise not open to question. The validity of these two postulates, which form part of the 
Malthusian doctrine, is not open to question, but a third postulate, which states that the rate of increase of populations invariably tends to outstrip the rate of increase of the available food supply, has lost much of its original force, owing to changed conditions, in respect of food production and food distribution, consequent upon modern scientific developments. Nevertheless, it is argued that since there must be a limit beyond which the food supply cannot be increased, and since there is no limit to the multiplication of man, the time must eventually arrive when "the inexorable laws of Malthus" must come into effective operation. But there is reason to doubt whether this proposition can any longer be sustained. In the first place, it has been shown that there is a definite limit to the multiplication of man, and that, in fact, as populations approach maturity their rate of growth tends to slow down until it may finally cease altogether. Secondly, although there must be a limit beyond which the food supply cannot be increased, it is not easy, in view of the small area of the world at present efficiently cultivated, and of the effect of scientific discoveries in augmenting the food supply, to predict with any certainty when, if ever, this limit will be reached. It is, in fact, impossible at present to place any limit upon the time when the food supply will fail or upon the population that the world will eventually be able to support.

Nevertheless, it is clear that one important factor determining the local density of a population at any given moment is the available food supply: thus the food supply within reach of the primitive inhabitants of an inhospitable area, with no knowledge of agriculture, must necessarily be restricted, and the density of such a population, in spite of high natality, must in consequence remain low. It likewise follows that with the discovery of agriculture, the productivity of the soil would be enhanced and the land would become capable of supporting a larger population. It is further clear that every successive increase in the intellectual sphere would increase the means of livelihood, and enable the land to support a larger population. The higher density associated with the adoption of modern agricultural methods, such, for example, as the employment of irrigation and of soil fertilisers, is thus dependent upon mental growth. A further stage of mental growth is represented by industrial developments, which in turn permit of the higher density associated with urbanisation. It would thus appear that, after a certain stage of population growth has been reached, the permissible limit of population density increases pari passu with mental development, and it is mainly because intellectual development has proceeded at a relatively rapid rate in the temperate zone that the density of the population is usually greater in this zone than it is in countries where the climatic conditions enable the subsistence needs of the population to be met at the expenditure of relatively little physical and mental energy. It is thus clear that the two important factors determining the density of populations are the fertility of the soil and the mental and physical energy and intellectual capacity of the population, and, of these, the latter, after a certain stage of growth has been reached, becomes the more 
important factor. The population density may thus be low either on account of the lack of fertility of the soil, or the lack of physical and mental energy of the population. On the other hand it may be high on account of the great productivity of the soil, or the great energy and intellectual capacity of the people. The actual density in any given area at any given time, being dependent upon various permutations and combinations of these two factors, is not a fixed quantity, and hence density per se is not capable of throwing light upon the biological structure of populations, and it has not in consequence been possible to include a density index in Table I. But if these two factors constitute the main determining factors of population density, they give no indication of the maximum population an area is capable of supporting. The density figure, in fact, merely represents the actual number per unit of area present at a given moment, and the only inference that can be drawn from this figureif it is constant for any length of time-is that under the conditions prevailing at the time the population in question is adjusted to its biological environment. In order to throw light on how near the population is to "saturation point" it is necessary to examine the vital statistics, more especially in respect of the birth-rate and the death-rate, over a series of years, since it may be assumed that if the food supply be deficient the population will cease to grow or its rate of growth will be extremely slow. A famine-due to climatic aberrations-affords an example of acute but temporary over-population occasioned by a sudden decline in the means of subsistence. The first statistical sign of the onset of a famine is a rise of the death-rate, more especially of the age groups at the extremes of life, which is followed by a decline in the number of live births. In these circumstances it would be expected that the smaller degrees of economic stress associated with over-population would exercise a similar, if less conspicuous, effect upon the vital statistics. It is at any rate scarcely conceivable that, in the presence of permanent over-population, the birth-rate should continue to rise and the death-rate to fall. On the contrary it must be assumed that so long as the vital statistics exhibits these features, the country in question is under- rather than over-populated. It is necessary to emphasise this point, since it is widely held that India is over-populated, and that the effect of any further increase of population will be to upset the balance of nature and to threaten the whole structure of its civilisation. It was, in fact, estimated in 1927 that "saturation point" would be reached in India when the population reached 330 millions, and that any further increase of population would entail grave consequences. Nevertheless, in spite of the fact that the population numbered 353 millions in 1931 and that since this date it has continued to increase at the rate of about $3 \frac{1}{4}$ millions a year, the birth-rate is still rising, the death-rate has shown a tendency to fall, and economic stress, so far as the rural population is concerned, has been conspicuous by reason of its absence. It is, in fact, held that the 10 per cent. increase of population during the last decennium, and the more recent increase, is incompatible with the existence of over-population, and it is further con- 
cluded that, even if the figure 400 millions be reached, as predicted, in the year 1941-an assumption which postulates the continuance of the present remarkable freedom from epidemics-it would not justify the conclusion that India would, even then, be over-populated ${ }^{1}$. On the contrary, the facts appear to justify the conclusion that India is under-populated, and that, as the result of modern developments in the sphere of agriculture, irrigation and industries, etc., the food supply has outstripped the population, with the result that a void exists, which, thanks to an unusual freedom from epidemics, is at the moment being filled at an exceptionally rapid rate.

Another factor affecting population density (apart from migration) is the death-rate; if the latter be high, as in British India, the rate of population growth must necessarily be slow, in spite of a high birth-rate. A high deathrate in association with an even higher birth-rate thus implies a grave waste of human life and energy, and, as such, is inimical to the mental growth and development of populations. It seems, however, permissible to conclude, as a general proposition, that population density tends to increase pari passu with mental development without at any time, under normal conditions, exceeding the "saturation point." Nevertheless, any sudden and drastic failure of the food supply, as the result of wars or famines, may be expected to occasion acute but temporary over-population, whilst any sudden deterioration of economic conditions, as the result, for example, of trade depression, will have a similar result. But, apart from variations in density due to temporary causes, a population must be expected to exhibit a steady decline both in power and in numbers as the result of its failure to exhibit mental growth and development and thus to adjust itself to a slowly changing biological environment; and herein perhaps is to be found the main factor determining the decline and eventual disappearance of decadent races. "The true greatness of a State," remarked Bacon, "consisteth essentially in population and in breed of men," and it must be concluded that, as population growth proceeds, the latter becomes of steadily increasing importance as the factor determining the density of populations.

\section{The natural history of populations}

The time has not yet arrived for the formulation of a general law of populations, but it is thought that the train of thought engendered by this study of the population problem renders it permissible to put forward a working hypothesis regarding the natural history of populations. It is held that substantial grounds exist for the belief that a population must be regarded, not as a haphazard mass of multiplying mankind, but as a biological entity possessing a definite structure, and capable of growth and development along

1 The terms "over-population" and "under-population" are used here and elsewhere in reference to subsistence level, but some modern writers employ these terms to connote a departure from the "optimum population," which is defined as the population associated with the maximum return per head of population in industry and agriculture.

Journ. of Hyg. xxxiv 
preordained lines. So far as structure is concerned, it has thus been shown that populations exhibit well-defined structural features, on the basis of which distinctive population types can be differentiated. It is further held that these distinctive population types represent populations at different stages of population growth and that all populations pass through definite stages of growth, so that it may be said that all the world is a stage, and all the populations in it are the players, each population in its turn plays many parts, the acts being the several stages of growth from infancy to old age. We may thus distinguish primeval, nascent, immature, mature, and senescent populations. In respect of function it has been shown that certain natural forces are concerned in determining population growth. It is held that the urge of prolificity constitutes the "prime mover," and it has been shown that this force or urge is not constant at all stages of population growth, being most evident in primeval populations and least conspicuous in populations at or near maturity. Another force of scarcely less importance than prolificity in determining population growth is mental development, when rate of growth, it has been shown, is also characterised by its inconstancy.

Opposed to the natural forces concerned in determining the increase of populations are those concerned in checking their growth, one of the most important of which is the means of subsistence. The action of this force, it has been shown, is also characterised by its inconstancy, so that under normal conditions a population does not tend to outstrip its food supply but remains, at all stages of population growth, adapted to its biological environment. It is thus concluded that the growth and development of populations is dependent upon well-defined natural forces, and that all the structural and functional changes associated with the growth and development of populations are explicable in terms of the action of these forces. Population growth is thus held to be controlled by a definite mechanism whose modus operandi constitutes the natural laws of populations.

But just as structure and function afford evidence of the existence of a Plan, so it is difficult to conceive of a Plan without a Purpose. There are, indeed, many facts pointing to the conclusion that this Purpose is the progressive evolution of the human race.

Thus, at the earliest and most critical period in natural history of populations, the urge of prolificity is intensely strong and far stronger than it is at any other period of population growth. At this period, however, the "field of selection" is, ex hypothesi, small; nevertheless, the rapid "turn-over" of the population associated with a short mean duration of life, a short interval between generations, high birth-rate and high death-rate, is conducive to the selection of those best adapted to survive in the particular environment in which they are placed.

In such populations the qualities possessing the greatest "survival value" are predominantly those physical attributes which will ensure the survival of the tribe and protect it from its human and other enemies. 
In nascent populations the biological environment is not dissimilar. The birth-rate and death-rate may both be high, but if the toll of life, and in particular of female and infant life, be heavy, yet Nature, "so careless of the single life," by providing a wide field of selection, is at least "careful of the type." The field of selection, although wide, may, however, be relatively barren, which may, in part at least, be due to the fact that, where the subsistence needs of a population can be met with little effort, one of the stimuli necessary to mental development is lacking.

The next stage of population growth is associated with progressive mental development and with the great increase of population thereby rendered possible. In the case of immature populations, the field of selection, already wide, is made wider by the intense competition associated with the struggle for existence. In this struggle physical force is no longer the main or even the predominant factor, since the survival of the population mainly depends upon the selection of those whose creative genius is capable of promoting the prosperity and well-being of the population. Nevertheless, the survival of the race must always depend upon its power to protect itself from its enemies, and hence its continued existence is dependent upon the virility as well as the mental vigour and energy of the population.

But however intellectually and physically efficient a population may be, it is not capable, on the basis of physical force alone, of making any permanent contribution to the progressive evolution of mankind, and so long therefore as a population has not shed the attributes of the earlier "tooth and claw" stage of civilisation, it cannot be regarded as possessing "survival-value" for the world at large.

The present hypothesis therefore assumes that the progressive evolution of the human race depends upon the survival of those populations-here denominated mature-which, whilst retaining the mental and physical vigour of immature populations, are capable, as the result of developments in the moral and intellectual sphere, of making a contribution to the welfare of mankind.

\section{BIOLOGICAL IMPLICATIONS OF BIRTH-CONTROL}

If the conclusions reached in the preceding pages be even approximately accurate, the biological implications of artificial birth-control are readily deducible. It is clear that, inasmuch as the restriction of births involves interference with the growth and development of populations, the practice of artificial birth-control must be regarded as suspect on biological grounds. Nevertheless, it is obvious that the biological implications of birth-control are not identical in all types of populations. Thus, in the case of a primeval community, in which prolificity, as a means of race survival, is a biological necessity of paramount importance, birth-control in any shape or form would constitute racial infanticide, and, as such, it would properly be regarded as a crime. It is, however, clear that artificial birth-control could never make headway 
in such a community, since, where race survival is a biological necessity, the urge of prolificity is so overpowering that it overrides all other considerations. In these circumstances it is not surprising that Onan, the son of Jacob, was slain for failing to raise up seed to his brother. It is, however, alleged by many writers that abortion, infanticide, and prolonged abstention from sexual intercourse, were and are still widely practised by primitive races in order to restrict their numbers; but, although it may be true that these practices have prevailed to a limited extent amongst many races-in the city-states of ancient Greece, for example, and during the decline of the Roman Empire-there is little or no reliable evidence that birth-control has ever been extensively practised by primitive races for the purpose of restricting population growth. It is still more improbable that savages should ever have practised birthcontrol by deliberately abstaining from sexual intercourse for prolonged periods; but, if so, they have shown themselves capable of exercising a restraint that the modern demand for contraceptives shows is unusual amongst highly civilised races at the present day. So far as primeval communities are concerned, the question of birth-control as a practical proposition may therefore be dismissed from consideration.

In the case of nascent populations, the biological implications of birthcontrol are less self-evident. Nevertheless, it is clear that, if the significance of the population plexus of British India has been correctly interpreted, any appreciable reduction of the birth-rate, unless it is also associated with a corresponding reduction of the death-rate, must, if long continued, place a check upon progressive evolution. The alternative, in fact, appears to lie between restricting the population artificially to its present cultural level at a figure somewhere above subsistence level-which may, perhaps, be regarded economically (but not biologically) as the optimum population-and providing for the progressive increase of the population so as to bring into play the stimulus to mental growth and development associated with intensive competition and the struggle for existence. It is held that the latter is biologically and in all other respects the correct policy, and, if this conclusion be sound, then it is clear that the practice of birth-control in rural India, which it is held is already under-populated, must be regarded as open to grave objection. It is indeed held that the future progress of India in the scale of civilisation is dependent, not upon restricting the number of births, but, for the present at any rate, upon increased natality, in association with measures designed to promote the moral, intellectual, and material welfare of its people.

On these grounds it is held that any action by the State to promote the practice of birth-control in India, by popularising the use of contraceptives, would be both a political crime and a biological blunder. But here again the voice of the people appears to give unconscious expression to the true biological needs of India. No one acquainted with rural India can doubt that the vast majority of the female population would be strongly opposed to any measures designed to restrict the size of their families, and there can be little doubt that 
the Burmese lady member of the Burma Legislative Council, in requesting Government to take immediate steps to forbid the sale of contraceptives, gave expression to the real sentiments of the vast majority of her sex and race. The demand, in so far as any demand exists at present, is not that childbirth should be restricted, but that it should be made safer, that child marriages should be forbidden, and that the conditions of life should be made healthier and happier for Indian womanhood.

The biological implications of artificial birth-control in mature populations are on a different footing. In such populations, it has been shown, natural birth-control is already in operation, and it is clear that, since the artificial restriction of births merely accentuates and accelerates the slowing down of the rate of growth of populations approaching maturity, no biological distinction can be drawn between neo-Malthusianism and the natural means whereby the fertility of maturing populations is automatically reduced.

Nevertheless, although a population may have reached maturity as regards numbers, it is still capable of growth in the moral and intellectual sphere, and since the progress of civilisation depends upon such growth, it is essential that those nations, and more particularly those elements of a nation that possess "survival value" for the world at large, should not disappear. On these grounds it is held that it would be a disaster for the future progress of civilisation if the great and unique contribution to the welfare and happiness of mankind, which has been and is now being made by men of British race, and more particularly by its English and Scottish elements, were to cease as the result of race suicide.

It may however, be argued that the section of the population to whom the technique of birth-control is now being taught embraces those classes whose "survival value" is of relatively small importance. But, since Nature requires a wide field of selection, it is essential that nothing should be done to dry up the reservoir from which has sprung many men who have made some of the greatest contributions to human progress. The encouragement of the practice of birthcontrol amongst the masses is therefore bjologically reprehensible, but in a matter of this nature each person must be allowed to exercise his individual judgment, and it may well be that in decadent families with no "survival value" the practice of birth-control, as well as voluntary sterilisation, is biologically beneficial. Nor can any serious objection be raised to a limited restriction of the size of families by "spacing" births, since the reduced number of births in modern England is largely made good by the great reduction in infantile mortality. Nevertheless, the promotion of birth-control under official auspices and with the aid of public funds amongst the general mass of the population of England and Scotland must be regarded as open to grave objection on biological grounds, and more especially is it reprehensible when many biologically immature populations are, for militaristic or political reasons, straining every nerve to increase their numbers. But if birth-control is to be practised on eugenic or on any other grounds, it is not necessary that 
it should be limited to the employment of contraceptives. It is indeed for consideration whether the induction of abortion, under proper safeguards, should not be legalised. There is no difference, biologically or ethically, between artificial birth-control and artificially induced abortion, nor can any serious objection be raised to artificial abortion from the moral point of view, provided it is carried out before the birth of a viable child is possible. It would indeed seem to be illogical that a State that countenances the use of contraceptives should continue to treat as a criminal offence an alternative method of preventing childbirth. On humanitarian grounds also this proposal has much to commend it. It is probable that only a small fraction of the disasters associated with clandestine illegal operations, performed under highly unfavourable conditions and at exorbitant charges by the least reputable members of the medical profession, come to light in the Coroner's Court. Surely, the time has come when it should be permissible for a married woman, if she so wishes, to submit in the light of day to an operation, which in skilled hands and under proper conditions, is both simple and safe; and surely the time has arrived when an archaic law, designed to meet the needs of primeval communities, but which is an anachronism in modern England, should be repealed.

\section{Conclusion}

It is not intended, on the basis of this preliminary study of a large and complex problem, to draw up a formal list of conclusions. Moreover, the hypothesis regarding the mechanism of population growth is admittedly tentative, and the main justification for putting it forward is the hope that it may engender a train of thought that will ultimately lead to the attainment of a fuller knowledge of mankind by man. But it would be idle to deny, if the views put forward in this paper are even remotely accurate, that current ideas regarding the nature of the population problem will have to be revised and a new significance will have to be attached to many old and familiar facts. In concluding this paper, it may therefore not be out of place to refer to some of the more important implications arising out of this study. There is no need to refer again to the biological implications of birth-control, and it will suffice to state that, if the natural history of populations is consistent with the existence of a Purpose and a Plan, the artificial restriction of births, as a means of decreasing the rate of population growth, is calculated to circumvent that Purpose and to defeat that Plan.

Perhaps the implication of most far-reaching importance arising out of this study has reference to the doubt cast upon the validity of certain aspects of the Malthusian doctrine. It is, in fact, held that the doctrine that all populations tend to increase at a greater rate than the means of subsistence is no longer tenable, and that, in consequence, all the inferences based thereon, which have dominated thought and speculation upon the population problem for over 100 years, fall to the ground. In short, it is held that the "inexorable laws of Malthus" are no longer inexorable, and that it is now no longer necessary 
to regard poverty, misery, and social degradation as an inevitable or even as a probable result of the progress of civilisation and the increase of mankind. But not only is it held that the gloomy prognostications of Malthus and his modern disciples may confidently be discarded, but it is permissible to believe that a happier and kindlier fate awaits mankind.

It has thus been shown that vegetative increase is associated, although at a slow, uneven, and uncertain pace, with mental growth and development, and that each successive stage of growth is compatible, not only with a larger population at a higher cultural level, but with a healthier, happier, and more prosperous population. It may be that the path of evolutionary progress will be long and tortuous and that dire evils will periodically overtake the world as the result of the "growing pains" of nascent and immature populations, but it is nevertheless possible to regard the future with hope and even with confidence. It is, in particular, no longer permissible to regard war amongst civilised races as a biological necessity, for not only do the laws of population growth provide automatically for the displacement and eventual disappearance of decadent peoples, but the teachings of biology point to the conclusion that the only real and lasting method of conquest lies in the moral and intellectual sphere.

The next most important implication to which the present hypothesis gives rise has reference to the significance to be attached to the steady growth of population, which, there is reason to believe, has in some countries become a source of embarrassment to the public health authorities who have found themselves placed in the illogical position of carrying out a policy which, if successful, is calculated to add to the sum of human misery. Fortunately it is now possible to dispose of this bogey, for, if the views put forward in this paper be correct, it follows that the steady growth of immature populations is an essential factor in the progressive evolution of the human race.

It is true that a sudden increase of the population, as the result of immigration or of a large rise of the birth-rate, which may occur at any stage of population growth, may occasion hardships, and it is likewise true that a sudden rise in prices may lead to economic stress and even to famine, but such occurrences are relatively rare and they can be mitigated, if not remedied, by appropriate administrative action. It must also be admitted that the larger the population the greater the toll likely to be exacted by endemic and more particularly by epidemic diseases, but, although these calamities have in the past and may again in the future decimate populations, it is no longer permissible to regard calamities of this nature, any more than warfare, as biological necessities designed by Nature to limit the inordinate multiplication of man. On the contrary, the views put forward in this paper envisage plague, pestilence, war, and famine, as deplorable incidents or regrettable accidents whose untimely intervention is calculated to check the growth and development of populations. There is, perhaps, one useful purpose that these calamities may serve. History shows that the havoc wrought by epidemics has been the 
means of stimulating mental development with a view to the discovery of means of preventing their recurrence, whilst the Great War was similarly responsible for intensive mental and physical efforts on the part of the combatants not only to win the war, but, in the case of enlightened nations, to prevent the occurrence of future wars. There are, however, other means equally efficient but less drastic of stimulating mental growth and development, and it is surely not necessary in the modern civilised world that every small advance should have to be purchased at the price of a holocaust.

Then again, implications of particular importance to statesmen and politicians, who are not always biologists, attach to the recognition of population types. It is clear, since all populations are not on the same biological footing, that political theories and administrative measures which may admirably be adapted to the needs of nations in an advanced stage of population growth may be wholly unsuited to nascent populations, and vice versa. Finally, the recognition of population types is of particular interest to the public health administrator. It is, in fact, clear that the significance attaching to vital statistics varies greatly in accordance with the type of population. Thus it is usually held that a high birth-rate constitutes one of the best indications of the good health of the community, although it is admitted that the rule does not always apply in eastern countries.

It is now clear that a high birth-rate, in the case of nascent populations, may merely imply that the country is under-populated and that conditions are favourable to an increase of population, and that it throws little or no light upon the state of health of the country Indeed, a high birth-rate in association with a high death-rate implies a grave waste of human energy and human life, which obviously cannot be regarded as a satisfactory state of affairs. Again, a declining birth-rate is usually held to be a sign that all is not well with the health of a population. We now see that it may merely mean that the population is approaching maturity and that it affords no indication of the state of the public health, which may, in fact, be steadily improving.

Then again, a steady decline of the death-rate is usually regarded as a sign of an improved state of the public health, but, in the case of a population about to reach maturity, the decline of the death-rate may be attributable to the change in the age composition of the population (as the result of a previous decline of the birth-rate), and in such circumstances it would not necessarily be indicative of any change in the state of health of the population.

On the other band, a rise of the death-rate in a nascent population might merely be dependent upon a rise of the birth-rate, and in such circumstances it might be consistent with an improvement and not a deterioration in the state of the public health.

These few examples suffice to indicate that the recognition of the existence of population types is or may be a matter of importance in the interpretation of vital statistics. 


\section{RELEVANT PUBLICATIONS}

Annual Report of the Chief Medical Officer of the Ministry of Health, London (1929, 1930 and 1931).

Annual Report of the Public Health Commissioner with the Government of India (1930 and 1931). Public Health Report, Punjab, 1931.

Encyclopaedia Britannica, 22, 1911. Article on "Population."

Transaction of Seventh Congress, Far Eastern Association of Tropical Medicine, 1927, 1. Article on "Population and Public Health in India," by Lieut.-Col. A. J. H. Russell, C.B.E., M.A., M.D., D.P.H., I.M.S.

"Birth-control in Asia." Brit. Med. J. (2. xii. 1933), ii, 1038.

(MS. received for publication 31. vII. 1934.-Ed.) 